\title{
Migrating Partial Seizures in Infancy
}

National Cancer Institute

\section{Source}

National Cancer Institute. Migrating Partial Seizures in Infancy. NCI Thesaurus. Code C125387.

A very rare severe form of epilepsy with poor prognosis that usually beg ins within a few weeks of birth. The seizure activity can appear in multiple locations in the brain or migrate from one region to another during an episode. It results in severe developmental delay. 